\title{
Cannabis Use and Its Social Correlates among In-School Adolescents in Algeria, Morocco, Palestine, Peru, and Tonga
}

\author{
Karl Peltzera,b,c \\ Supa Pengpida,b
}

aASEAN Institute for Health Development, Madidol University, Salaya, Phutthamonthon, Nakhonpathom, Thailand, 73170 bUniversity of Limpopo, Turfloop Campus, Sovenga 0727, South Africa cHIV/AIDS/STIs/and TB (HAST), Human Sciences Research Council, Private Bag X41, Pretoria 0001, South Africa Doi:10.5901/mjss.2014.v5n9p558

\begin{abstract}
The aim of this study was to assess the prevalence of cannabis use and associated factors among school-going adolescents in Algeria, Morocco, Peru, Palestine and Tonga. Using data from the Global School-Based Student Health Survey (GSHS), we assessed the prevalence of cannabis use and social correlates among adolescents $(N=15226)$. The overall lifetime cannabis use was 3.2\% and current cannabis use was 2.6\%. Lifetime and current cannabis use was higher in Tonga $(7.5 \%$ and $6.8 \%$, respectively) than in any other of the five study countries. Variables positively associated with the outcome in multivariable analysis were male gender, poverty (went hungry), current smoking, having been in a physical fight, had an injury, and frequent consumption of fast food. Efforts to prevent and control cannabis use may need to address a cluster of risk behaviours, in particular cigarette smoking.
\end{abstract}

Keywords: Prevalence; Cannabis use; In-school; Adolescents; Algeria, Morocco, Palestine, Peru, Tonga

\section{Introduction}

Cannabis is the most common used illicit drug globally and its use appears to be increasing in developed and developing countries (Hall \& Degenhardt, 2007). Cannabis use, and particularly heavy use, is associated with increased rates of a range of adjustment problems in adolescence and young adulthood such as other illicit drug use, crime, depression and suicidal behaviours (Fergusson, Horwood \& Swain-Campbell, 2002). Early and regular cannabis use in adolescence increases the risk of cannabis dependence which in turn predicts the development of mood and psychotic disorders (Hall \& Degenhardt, 2007).

Cannabis use among adolescents has been reported as $8.1 \%$ past month in 35 European and Northamerican countries (Sznitman et al., 2013), 14.6\% past year in 32 European countries (Piontek, Kraus, Bjarnason, Demetrovics \& Ramstedt, 2013), with variations from $27.5 \%$ in Czech Republic in the past year, $11 \%$ in Germany used cannabis in the last 12 months (Richter, Pförtner, Lampert \& HBSC-Team Deutschland, 2012) and in Canada 47\% had used cannabis in their lifetime (Tu, Ratner \& Johnson, 2008). Regarding cannabis use in low and middle income countries, some studies have reported $37.2 \%$ ever-used cannabis in Zambia (Siziya et al., 2013) and 19.2\% among boys and 3.7\% among girls had used cannabis in the past month in the Seychelles (Alwan, Viswanathan, Rousson, Paccaud \& Bovet, 2011). There is a lack of national studies on cannabis use among adolescents in other low and middle income countries. According to the World Drug Report (UNODC 2010) the annual prevalence of cannabis use in 15-65 year olds were in some low and middle income countries, such as in Algeria 5.7\% and Morocco 4.2\% in North Africa, Peru 0.7\% in South America and no data on Occupied Palestinian Territory (Israel 8.9\%) in The Near and Middle east, no data on Tonga (Fiji 5.1\%) in Oceania.

Risk factors for cannabis use among adolescents have been identified as follows: 1) sociodemographic factors (male gender Sznitman et al., 2013; Tu et al. 2008; younger age (Siziya et al., 2013), lower economic status (Legleye, Beck, Khlat, Peretti-Watel \& Chau, 2012; Tu et al., 2008); 2) Other drug use (alcohol, Faeh, Viswanathan, Chiolero, Warren \& Bovet, 2006; Siziya et al., 2013; Tu et al., 2008; smokers, Faeh et al., 2006; Tu et al., 2008); 3) Other health risk behaviours (Bullying/fighting (Siziya et al., 2013; Sznitman et al., 2013); truancy (Alwan et al. 2001); history of having engaged in sexual intercourse (Siziya et al., 2013); Dietary factors (high-fat food intake, Arcan, Kubik, Fulkerson, Hannan \& Story, 2011; not being obese, Hayatbakhsh, O'Callaghan, Mamun, Williams, Clavarino \& Najman, 2010); low levels of physical activity (Delisle, Werch, Wong, Bian \& Weiler, 2010); 5) Injury (Barrio, Jiménez-Mejías, Pulido, Lardelli-Claret, 
Bravo MJ \& de la Fuente, 2012); 5) Psychosocial factors (Alwan et al., 2011), and 6) Parental and school factors (Siziya et al., 2013; Sznitman et al., 2013; Tu et al., 2008).

Therefore, the aim of this study was to assess the prevalence of cannabis use and associated factors among school-going adolescents in Algeria, Morocco, Peru, Palestine and Tonga using the Global School-Based Health Survey (GSHS).

\section{Method}

\subsection{Participants and procedures}

For this study existing data from the Global School-Based Health Survey (GSHS) from two North African countries (Algeria and Morocco), one country in the Near and Middle East (Palestine), one country in South America (Peru) and one country in Oceania (Tonga) were utilized. Details of the study and the data are publicly available and can be accessed at http://www.who.int/chp/gshs/methodology/en/index.html. The GSHS school-based survey used a design of two-stage cluster sampling to gather data to represent all children within grades 6 to 10 in each study country. At stage one of the sampling, schools were sampled with probability proportional to their enrollment size. At stage two of the sampling, classes in the sampled schools were randomly chosen and all children in the sampled classes were eligible to participate. School children were asked to complete a questionnaire during one classroom period (Centers for Disease Control, 2013).

\subsection{Measures}

Cannabis use was assessed with two questions: 1) "During your life, how many times have you used Marijuana (also called country examples)?" and 2) "During the past 30 days, how many times have you used marijuana (also called country examples)?" Response options ranged from 1=0 times to $5=20$ or more times (Centers for Disease Control, 2013).

Smoking: "During the past 30 days, on how many days did you smoke cigarettes?" Response options ranged from $1=0$ days to $7=a l l ~ 30$ days. (Centers for Disease Control, 2013).

\subsection{Dietary behaviour}

Hunger: During the past 30 days, how often did you go hungry because there was not enough food in your home? Response options were from $1=$ never to $5=$ always (Centers for Disease Control, 2013).

Carbonated soft drinks: "During the past 30 days, how many times per day did you usually drink carbonated soft drinks such as country specific examples?" Response options ranged from $0=1$ did not drink any carbonated soft drinks in the past 30 days to $6=5$ or more times per day (Centers for Disease Control, 2013).

Eating food from a fast food restaurant: "During the past 7 days, on how many days did you eat food from a fast food restaurant, such as such country specific examples?" Response options ranged from 0 days to 7 days (Centers for Disease Control, 2013).

Body Mass Index (BMI). Body weight and height were assessed by self-report. School children with BMI figures relating to an adult BMl of $<25.0 \mathrm{~kg} / \mathrm{m} 2$ were categorized as having normal weight and those with a BMl of $\geq 25.0 \mathrm{~kg} / \mathrm{m} 2$ were categorized as having overweight, while those with a BMI value of $\geq 30.0 \mathrm{~kg} / \mathrm{m} 2$ ) were classified as obese. For the BMI cut-points used to define the different weight classifications international age- and gender-specific criteria were used (Cole, Bellizzi, Flegal \& Dietz, 2000).

Physical Activity: "During the past 7 days, on how many days were you physically active for a total of at least 60 minutes per day?" and "During a typical or usual week, on how many days are you physically active for a total of at least 60 minutes per day?" Physical inactivity was defined as four or less days at least 60 minutes per day physically active in a week. (Centers for Disease Control, 2013).

Being in a fight: "During the past 12 months, how many times were you in a physical fight?" (1 time to 12 or more times). Bullied: "During the past 30 days, on how many days were you bullied?" ( 1 or 2 days to all 30 days). "During the past 12 months, how many times were you seriously injured?" (one or more times). (Centers for Disease Control, 2013).

Injury: "During the past 12 months, how many times were you seriously injured?" (Serious injury was defined as "when it makes you miss at least one full day of usual activities (such as school, sports, or a job) or requires treatment by a doctor or nurse). Eight options were provided, ranging from 1=0 times to $8=12$ or more times. A response of " 0 " was 
described as not having sustained a serious injury, while a response of one or more times was classified as having experienced a serious injury.

\section{Data Analysis}

STATA software version 11.0 (Stata Corporation, College Station, TX, USA) was used to conduct data analysis. Logistic regression was used for estimating the impact of explanatory variables (sociodemographic and health risk behaviour variables) for past month cannabis use. All variables which were statistically significant $(P<.05)$ in bivariate analyses were included in the multivariable model. The $95 \%$ confidence intervals and P-values are adjusted for the multi-stage stratified cluster sample design of the study.

\section{Results}

\subsection{Sample characteristics}

The sample included 15226 school going adolescents primarily between 13 to 16 years of age from Algeria, Morocco, Palestine, Peru and Tonga. There were slightly more male (50.8\%) than female students (49.2\%), $7.6 \%$ reported that they most of the time or always went hungry, and $11.5 \%$ were current smokers. More than two in five (41.8\%) had been bullied in the past 30 days, $43.4 \%$ had been in a physical fight in the past 12 months and $37.5 \%$ had an injury in the past 12 months. The majority (78.6\%) were physically inactive, $62 \%$ had one or more soft drinks per day, $16.7 \%$ had eaten three or more times fast food in a week, and $3.3 \%$ were obese. The overall lifetime cannabis use was $3.2 \%$ and current cannabis use was $2.6 \%$. Lifetime and current cannabis use was higher in Tonga (7.5\% and 6.8\%, respectively) than in any other of the five study countries (see Table 1).

Table 1: Sample characteristics among adolescents in six countries

\begin{tabular}{|l|c|c|c|}
\hline & Total & Lifetime cannabis use & Past month cannabis use \\
\hline All & $\mathrm{N}(\%)$ & $\%(95 \% \mathrm{Cl})$ & $\%(95 \% \mathrm{Cl})$ \\
Country & 15226 & $3.2(2.6-3.9)$ & $2.6(2.1-3.2)$ \\
Algeria & & & \\
Morocco & $4532(29.8)$ & $2.3(1.5-3.0)$ & $2.2(1.3-3.0)$ \\
Palestine & $2924(19.2)$ & $3.7(2.5-4.9)$ & $2.6(1.6-3.5)$ \\
Peru & $2677(17.6)$ & $3.9(2.3-5.4)$ & $4.1(2.3-5.9)$ \\
Tonga & $2882(18.9)$ & $4.3(3.1-5.5)$ & $3.3(2.2-4.3)$ \\
& $2211(14.5)$ & $7.5(5.7-9.4)$ & $6.8(5.0-8.6)$ \\
\hline Age (years) & $\mathrm{N}(\%)$ & $\mathrm{N}(\%)$ & $\mathrm{N}(\%)$ \\
$\leq 13$ & & & \\
14 & $4797(33.6)$ & $135(1.8)$ & $140(1.9)$ \\
15 & $4033(24.1)$ & $116(2.8)$ & $107(2.5)$ \\
$\geq 16$ & $4062(25.2)$ & $150(3.5)$ & $120(2.6)$ \\
\hline Gender & $2177(17.0)$ & $131(6.2)$ & $98(4.4)$ \\
Female & & & \\
Male & $7763(49.2)$ & $156(1.0)$ & $130(0.9)$ \\
\hline Poverty or went hungry & $7263(50.8)$ & $368(5.3)$ & $329(4.2)$ \\
No (never, rarely, sometimes) & & & \\
Yes (most of the time or always) & $13693(92.4)$ & $436(3.0)$ & $364(2.4)$ \\
\hline Current smoking & $1399(7.6)$ & $96(5.7)$ & $98(5.3)$ \\
No & & & \\
Yes (any in the past 30 days) & $12979(88.5)$ & $166(1.1)$ & $126(0.8)$ \\
\hline Current being bullied & $1890(11.5)$ & $328(19.5)$ & $296(16.4)$ \\
No & & & \\
Yes & $7885(58.2)$ & $175(2.5)$ & $130(2.0)$ \\
\hline Fighting & $6634(41.8)$ & $322(4.1)$ & $293(3.3)$ \\
No & & & \\
Yes (1-12 or more times in the past 12 months) & $8571(56.6)$ & $144(1.4)$ & $119(1.1)$ \\
\hline Injury & $6522(43.4)$ & $385(5.6)$ & $339(4.5)$ \\
No & $8037(62.5)$ & $123(1.6)$ & \\
\hline
\end{tabular}




\begin{tabular}{|l|c|c|c|}
\hline Yes & $5275(37.5)$ & $326(5.7)$ & $293(4.6)$ \\
\hline Fast food consumption & & & \\
$<3$ times a week & $12620(83.3)$ & $375(2.7)$ & $325(2.3)$ \\
$\geq 3$ times a week & $2543(16.7)$ & $164(5.8)$ & $142(4.5)$ \\
\hline Carbonated soft drinks & & & $181(2.7)$ \\
None & $6276(38.0)$ & $222(3.5)$ & $284(2.6)$ \\
1 or more per day & $8855(62.0)$ & $316(3.1)$ & $398(2.6)$ \\
\hline BMl obesity & $13227(96.7)$ & $463(3.2)$ & $32(3.0)$ \\
No & $878(3.3)$ & $30(3.3)$ & $116(3.2)$ \\
Yes & & & $349(2.5)$ \\
\hline Physical activity & $3315(21.4)$ & $132(4.2)$ & $401(3.0)$ \\
$\geq 5$ or more days a week & $11655(78.6)$ & & \\
$<5$ days a week & & & \\
\hline
\end{tabular}

\subsection{Association between demographic and health risk variables and cannabis use}

In bivariate analysis, older age, being male, poverty (went hungry), current smoking, having been bullied, having been in a physical fight, had an injury, and frequent consumption of fast food were found to be associated with current cannabis use. In multivariable unconditional regression analysis male gender (Odds Ratio (OR) $=1.59 ; 95 \%$ Confidence Interval $(\mathrm{Cl})=1.04-2.42)$, poverty (went hungry) ( $\mathrm{OR}=1.75, \mathrm{Cl}=1.07-2.86)$, current smoking (OR=17.97, $\mathrm{Cl}=11.82-27.32)$, having been in a physical fight (OR=1.90, $\mathrm{Cl}=1.39-2.59)$, had an injury (OR=1.72, $\mathrm{Cl}=1.14-2.58)$, and frequent consumption of fast food (OR=1.45, $\mathrm{Cl}=1.01-2.08)$ were associated with current cannabis use (see Table 2).

Table 2: Bivariate and multivariable logistic regression analysis of factors that are associated with current cannabis use in six countries

\begin{tabular}{|c|c|c|c|c|}
\hline & UOR $(95 \% \mathrm{Cl})$ & P-value & AOR $(95 \% \mathrm{Cl})$ & P-value \\
\hline $\begin{array}{l}\text { Age (years) } \\
\leq 13 \\
14 \\
15 \\
\geq 16\end{array}$ & $\begin{array}{c}1.00 \\
1.35(0.84-2.18) \\
1.39(0.94-2.05) \\
2.40(1.43-4.03)\end{array}$ & $\begin{array}{l}0.214 \\
0.100 \\
0.001\end{array}$ & $\begin{array}{c}1.00 \\
1.23(0.70-2.18) \\
0.99(0.60-1.64) \\
1.42(0.77-2.60)\end{array}$ & $\begin{array}{l}0.469 \\
0.981 \\
0.257\end{array}$ \\
\hline $\begin{array}{l}\text { Gender } \\
\text { Female } \\
\text { Male }\end{array}$ & $\begin{array}{c}1.00 \\
5.03(3.39-7.48)\end{array}$ & 0.001 & $\begin{array}{c}1.00 \\
1.59(1.04-2.42)\end{array}$ & 0.032 \\
\hline $\begin{array}{l}\text { Poverty } \\
\text { No } \\
\text { Yes }\end{array}$ & $\begin{array}{c}1.00 \\
2.24(1.57-3.19) \\
\end{array}$ & 0.001 & $\begin{array}{c}1.00 \\
1.75(1.07-2.86)\end{array}$ & 0.025 \\
\hline $\begin{array}{l}\text { Current smoking } \\
\text { No } \\
\text { Yes }\end{array}$ & $\begin{array}{c}1.00 \\
25.09(18.60-33.84)\end{array}$ & 0.001 & $\begin{array}{c}1.00 \\
17.97(11.82-27.32)\end{array}$ & 0.001 \\
\hline $\begin{array}{l}\text { Current being bullied } \\
\text { No } \\
\text { Yes }\end{array}$ & $\begin{array}{c}1.00 \\
1.71(1.25-2.35)\end{array}$ & 0.001 & $\begin{array}{c}1.00 \\
0.99(0.71-1.36)\end{array}$ & 0.927 \\
\hline $\begin{array}{l}\text { In physical fight } \\
\text { No } \\
\text { Yes }\end{array}$ & $\begin{array}{c}1.00 \\
4.27(3.42-5.32)\end{array}$ & 0.001 & $\begin{array}{c}1.00 \\
1.90(1.39-2.59)\end{array}$ & 0.001 \\
\hline $\begin{array}{l}\text { Injury } \\
\text { No } \\
\text { Yes }\end{array}$ & $\begin{array}{c}1.00 \\
3.93(2.77-5.58)\end{array}$ & 0.001 & $\begin{array}{c}1.00 \\
1.72(1.14-2.58)\end{array}$ & 0.009 \\
\hline $\begin{array}{l}\text { Fast food consumption } \\
<3 \text { times a week } \\
\geq 3 \text { times a week }\end{array}$ & $\begin{array}{c}1.00 \\
2.06(1.56-2.72)\end{array}$ & 0.001 & $\begin{array}{c}1.00 \\
1.45(1.01-2.08)\end{array}$ & 0.046 \\
\hline $\begin{array}{l}\text { Carbonated soft drinks } \\
\text { None } \\
1 \text { or more per day }\end{array}$ & $\begin{array}{c}1.00 \\
0.99(0.72-1.34)\end{array}$ & 0.925 & -- & \\
\hline $\begin{array}{l}\text { BMl obesity } \\
\text { No } \\
\text { Yes }\end{array}$ & $\begin{array}{c}1.00 \\
1.17(0.57-2.40)\end{array}$ & 0.672 & -- & \\
\hline
\end{tabular}




\begin{tabular}{|l|c|c|c|c|}
\hline $\begin{array}{l}\text { Physical activity } \\
\geq 5 \text { or more days a week } \\
<5 \text { days a week }\end{array}$ & 1.00 & & & \\
\hline
\end{tabular}

\section{Discussion and Conclusion}

In this study of in-school adolescents in six low and middle income countries from different regions (North Africa, South America, Near and Middle East, Oceania) the overall lifetime cannabis use and current cannabis use was found to be lower than in previous studies in Europe, North America and sub-Saharan Africa (Alwan et al., 2011; Piomyek et al., 2013; Richter et al., 2012; Siziya et al., 2013; Sznitman et al., 2013; Tu et al., 2008). The study further found country variations in cannabis use, with lifetime and current cannabis use being the highest in Tonga $(7.5 \%$ and $6.8 \%$, respectively) compared to any other of the five study countries. Devaney, Reid, Baldwin, Crofts and Power (2006) note that cannabis is the by far the most common and widespread illicit drug used in the studied six Pacific Islands including Tonga, with even higher levels than in Australia and New Zealand (Howard, Ali \& Robins, 2011). Regular, reliable and routine monitoring of patterns and trends in cannabis use among young people in low and middle income countries can assist in identifying concerns and developing evidence-informed interventions to prevent, contain and treat current and any emerging issues (Howard et al., 2011).

In agreement with previous studies (Legleye et al., 2012; Sznitman et al., 2013; Tu et al. 2008), this study found that male gender and lower economic status were associated with cannabis use. The gender difference may possibly be attributed to social norms that tend to stigmatize girls over boys who engage in cannabis use and to a higher risk taken behaviour among boys than girls (Alwan et al., 2011; Croisant, Haque Laz, Rahman \& Berenson, 2013).

A major finding was that adolescents who engaged in current cannabis use were 18 times more likely to be current smokers. The co-occurrence of cannabis and tobacco use and misuse have been confirmed in previous studies (Agrawal, Budney \& Lynskey, 2012; Faeh et al., 2006; Tu et al., 2008). There is accumulating evidence that some mechanisms linking cannabis and tobacco use are distinct from those contributing to co-occurring use of drugs in general (Agrawal et al., 2012).

In agreement with some previous studies (Barrio et al., 2012; Sznitman et al., 2013), this study found that physical fighting and sustaining an injury were associated with cannabis use. The association between higher levels of cannabis use and higher levels of fighting might be related to an aggregation of cannabis use and fighting in the areas in the present study (Perra, Fletcher, Bonell, Higgins, \& McCrystal, 2012). Laboratory research indicates that cannabis impairs various behavioural and cognitive skills, which may increase the risk for injury (Macdonald et al., 2003). Yet, it appears that in this study specific behaviour types lead to increased injury in cannabis users, e.g., cannabis users had an 18 times higher risk to have had a gunshot wound in the past 12 months compared to non-cannabis users.

This study found in line with one other study (Arcan et al., 2011) that dietary factors in terms of frequent eating in fast food restaurants and possibly high-fat food intake). The issue of dietary behaviour needs further exploration. Unlike some previous studies (Delisle et al., 2010; Hayatbakhsh et al., 2010) this study did not find an association between obesity, frequent levels of physical activity and less frequent cannabis use. It is possible that is due to the findings that only a few were obese and engaged in frequent physical activity in this study.

\section{Limitations of the Study}

Due to the cross-sectional nature of the study causal inferences cannot be made. Further, the self-report of illicit drug use should be interpreted with caution; it is possible that respondents underreported illicit drug use, especially females. Moreover, several variables known to be related to cannabis use were not investigated, including alcohol use, truancy, sexual intercourse, psychosocial, parental and school factors (Alwan et al., 2001; Faeh et al., 2006; Siziya et al., 2013; Sznitman et al., 2013; Tu et al., 2008). Some of these variables are assessed in the GSHS but were not available for the study countries using cannabis.

\section{Conclusion}

We have estimated the prevalence of lifetime and current cannabis use amongst in-school adolescents in Algeria, Morocco, Palestine, Peru and Tonga. Public health intervention aimed to prevent cannabis use among adolescents should be designed with the understanding that cannabis use may be associated with other risk behaviours such as cigarette smoking, physical fighting, injury and dietary behaviour. 


\section{Acknowledgements}

We are grateful to the World Health Organization (Geneva) for making the data available to us for analysis. We also thank the Ministries of Education and Health and the study participants for making the Global School Health Survey possible in the study countries. The governments of the study countries and the World Health Organization did not influence the analysis, nor did they have influence on the decision to publish these findings.

\section{References}

Agrawal, A., Budney, A. J., \& Lynskey, M.T. (2012). The co-occurring use and misuse of cannabis and tobacco: a review. Addiction, 107(7), 1221-33.

Alwan, H., Viswanathan, B., Rousson, V., Paccaud, F., \& Bovet, P. (2011). Association between substance use and psychosocial characteristics among adolescents of the Seychelles. BioMedCentral Pediatrics,11, 85.

Arcan, C., Kubik, M. Y., Fulkerson, J. A., Hannan, P. J., \& Story, M. (2011). Substance use and dietary practices among students attending alternative high schools: results from a pilot study. BioMedCentral Public Health, 11, 263.

Barrio, G., Jiménez-Mejías, E., Pulido, J., Lardelli-Claret, P., Bravo, M. J., \& de la Fuente, L. (2012). Association between cannabis use and non-traffic injuries. Accident Analysis \& Prevention, 47, 172-6.

Centers for Disease Control (CDC) (2013). The Global School and Health Survey background [Online]. Available at http://www.cdc.gov/gshs/background/index, accessed 15 December 2013.

Cole, T. J., Bellizzi, M. C., Flegal, K. M., \& Dietz, W. H. (2000). Establishing a standard definition for child overweight and obesity worldwide: international survey. British Medical Journal, 320(7244), 1240-1243.

Croisant, S. A., Haque Laz, T., Rahman, M., \& Berenson, A. B. (2013). Gender differences in risk behaviors among high school youth. Global Advances in Health and Medicine, 2(5), 16-22.

Delisle, T. T., Werch, C. E., Wong, A. H., Bian, H., \& Weiler, R. (2010). Relationship between frequency and intensity of physical activity and health behaviors of adolescents. Journal of School Health, 80(3), 134-40.

Devaney, M. L., Reid, G., Baldwin, S., Crofts, N., \& Power, R. (2006). Illicit drug use and responses in six Pacific Island countries. Drug and Alcohol Review, 25(4), 387-90.

Faeh, D., Viswanathan, B., Chiolero, A., Warren, W., \& Bovet, P. (2006). Clustering of smoking, alcohol drinking and cannabis use in adolescents in a rapidly developing country. BioMedCentral Public Health, 6, 169.

Fergusson, D. M., Horwood, L. J., \& Swain-Campbell, N. (2002). Cannabis use and psychosocial adjustment in adolescence and young adulthood. Addiction, 97(9), 1123-35.

Hall, W., \& Degenhardt, L. (2007). Prevalence and correlates of cannabis use in developed and developing countries. Current Opinion in Psychiatry, 20(4), 393-7.

Hayatbakhsh, M. R., O'Callaghan, M. J., Mamun, A. A., Williams, G. M., Clavarino, A., \& Najman, J. M. (2010). Cannabis use and obesity and young adults. American Journal of Drug and Alcohol Abuse, 36(6), 350-6.

Howard, J., Ali, H., \& Robins, L. (2011). Alcohol, cannabis and amphetamine-type stimulants use among young Pacific Islanders. Drug and Alcohol Review, 30(1), 104-10.

Kokkevi, A., Nic Gabhainn, S., Spyropoulou, M., \& Risk Behaviour Focus Group of the HBSC (2006). Early initiation of cannabis use: a cross-national European perspective. Journal of Adolescent Health, 39(5), 712-9.

Legleye, S., Beck, F., Khlat, M., Peretti-Watel, P., \& Chau, N. (2012). The influence of socioeconomic status on cannabis use among French adolescents. Journal of Adolescent Health, 50(4), 395-402.

Macdonald, S., Anglin-Bodrug, K., Mann, R. E., Erickson, P., Hathaway, A., Chipman, M., \& Rylett, M. (2003). Injury risk associated with cannabis and cocaine use. Drug and Alcohol Dependence, 72(2), 99-115.

Perra, O., Fletcher, A., Bonell, C., Higgins, K., \& McCrystal P. (2012). School-related predictors of smoking, drinking and drug use: evidence from the Belfast Youth Development Study. Journal of Adolescence, 35(2), 315-24.

Piontek, D., Kraus, L., Bjarnason, T., Demetrovics, Z., \& Ramstedt, M. (2013). Individual and country-level effects of cannabis-related perceptions on cannabis use. A multilevel study among adolescents in 32 European countries. Journal of Adolescent Health, 52(4), 473-9.

Richter, M., Pförtner, T. K., Lampert, T. \& HBSC-Team Deutschland (2012). Changes in tobacco, alcohol and cannabis use by adolescents from 2002 to 2010 in Germany. Gesundheitswesen, 74 Suppl, S42-8.

Siziya, S., Muula, A. S., Besa, C., Babaniyi, O., Songolo, P., Kankiza, N., \& Rudatsikira, E. (2013). Cannabis use and its sociodemographic correlates among in-school adolescents in Zambia. Italian Journal of Pediatrics, 39:13.

Sznitman, S. R., Kolobov, T., Bogt, T. T., Kuntsche, E., Walsh, S. D., Boniel-Nissim, M., \& Harel-Fisch, Y. (2013). Exploring substance use normalization among adolescents: a multilevel study in 35 countries. Social Science and Medicine, 97, 143-51.

Tu, A. W., Ratner, P. A., \& Johnson, J. L. (2008). Gender differences in the correlates of adolescents' cannabis use. Substance Use and Misuse, 43(10), 1438-63.

United Nations Office on Drugs and Crime (UNODC) (2010). World Drug Report 2010. Vienna: United Nations Publication, Sales No. E.10.XI.13. 